\title{
Neosporosis en alpacas de la provincia de Huaytará, Huancavelica, Perú
}

\author{
Neosporosis in alpacas of the Huaytará province, Huancavelica, Peru
}

\author{
Rubens Santé1, Enrique Serrano-Martínez ${ }^{1,2}$
}

\section{Resumen}

El objetivo del estudio fue determinar la seroprevalencia de anticuerpos de N. caninum, mediante la técnica de Inmunofluorescencia Indirecta (IFI), empleando un punto de corte de 1:100, en 288 alpacas de varios centros poblados de la provincia de Huaytará, departamento de Huancavelica, durante 2016 y 2017. Se colectaron muestras de sangre y se levantó información situacional y epidemiológica de los rebaños muestreados. La seroprevalencia fue de $16.3 \pm 4.3 \%$ (47/288), sin diferencias significativas por efecto de procedencia, grupo etario y número de parto. Los resultados encontrados demuestran la presencia de anticuerpos específicos frente a $N$. caninum en la región.

Palabras clave: Neospora caninum; alpacas; Huancavelica; IFI

\section{ABSTRACT}

The aim of this study was to determine the seroprevalence of $N$. caninum antibodies, using the immunofluorescence antibody technique (IFAT), using a cut-off point of 1:100 in 288 alpacas from several populations in the province of Huaytará, Huancavelica, during 2016 and 2017. Blood samples plus situational and epidemiological information were collected. The seroprevalence was $16.3 \pm 4.3 \%$ (47/288), without significant differences due to origin, age group and parity. The results show the presence of specific antibodies against $N$. caninum in the region.

Key words: Neospora caninum; alpaca; Huancavelica; IFAT

${ }^{1}$ Grupo SANIVET, Facultad de Medicina Veterinaria y Zootecnia, Universidad Peruana Cayetano Heredia, Lima, Perú

${ }^{2}$ E-mail: enrique.serrano@upch.pe

Recibido: 26 de febrero de 2018

Aceptado para publicación: 20 de septiembre de 2018 


\section{INTRODUCCIÓN}

La alpaca constituye el principal medio de subsistencia de un gran sector de la población de las zonas altoandinas del Perú, por su aporte de fibra, carne y otros subproductos (FAO, 2005). El 95\% de estos animales se encuentra en manos de pequeños y medianos productores y el restante $5 \%$ en empresas u agrupaciones de productores (Aguilar et al., 2014).

La producción de alpacas se ve seriamente afectada por agentes infecciosos y parasitarios (Llanos y Morales, 2012; FAO, 2005), pues además de afectar la calidad y cantidad de fibra, carne y leche producida (Guerrero et al., 1994), causan bajas tasas de fertilidad, natalidad y elevadas tasas de mortalidad embrionaria y neonatal (Gallegos, 2013)

La neosporosis es una enfermedad parasitaria emergente producida por Neospora caninum, protozoario intracelular del Phylum Apicomplexa, Clase Sporozoea, Orden Eucoccidia y familia Sarcocystidae, que está estrechamente relacionado con Toxoplasma gondii (Dubey et al., 2002). Tiene un ciclo biológico heteroxeno facultativo que incluye un amplio número de hospedadores tanto domésticos como silvestres (Dubey et al., 2007). El perro, coyote (Canis latrans) y dingo (Canis lupus) son los hospederos definitivos, adquieren la infección al ingerir tejidos de los hospedadores intermediarios que contienen los quistes tisulares del parásito, llegando a eliminar los ooquistes del parásito con las heces (McAllister et al., 1998; Gondim et al., 2004). Los hospederos intermediarios (vacas, alpacas, ovejas, búfalos y ciervos) se infectan por vía transplacentaria y transmisión horizontal al ingerir los alimentos y el agua contaminado con el ooquiste de $N$. caninum (Dubey, 2003; Dubey et al., 2007).
El ciclo de vida de este parásito involucra 3 fases: taquizoíto, bradizoíto y esporozoíto (Atkinson et al., 2000). Las dos primeras están presentes en tejidos de los hospederos infectados (intermediarios y definitivos), mientras que los ooquistes están presentes en las heces del hospedero definitivo (Bjorkman y Uggla, 1999).

El diagnóstico de $N$. caninum se puede realizar a través de la reacción en cadena de la polimerasa (PCR), detectando el ADN del protozoario a partir de muestras de suero, leche, fluidos vaginales y saliva (Sager et al., 2001). La inmunohistoquímica (IHC) es la técnica más usada para demostrar la presencia de Neospora en los tejidos (Dubey y Lindsay, 1989). Por otro lado, las técnicas serológicas de inmunofluorescencia y ELISA han demostrado ser excelentes técnicas para la detección de anticuerpos frente a $N$. caninum (Baszler et al., 1996; Packham et al., 1998).

Uno de los primeros hallazgos de $N$. caninum en camélidos sudamericanos (CSA) fue reportado en pequeñas comunidades del centro del Perú, encontrando que $42.4 \%$ de alpacas y $18.4 \%$ de llamas seropositivas a $N$. caninum mediante la técnica de IFI con un punto de corte 1:50 (Chávez et al., 2002). Posteriormente, Serrano-Martínez et al. (2007) confirmaron la presencia de $N$. caninum en 14 de 50 fetos $(28 \%)$ de la región sur y centro altoandina mediante inmunohistoquímica. Por otro lado, Wolf et al. (2005) encontraron una prevalencia de $3.1 \%$ en alpacas de Quimsachata, Puno, mediante IFI y ELISA. Con base a esto, el presente estudio tuvo como objetivo cuantificar la prevalencia de anticuerpos séricos frente a $N$. caninum mediante la técnica de Inmunofluorescencia Indirecta (IFI) en alpacas de comunidades ganaderas de la provincia de Huaytará, Huancavelica. 


\section{Materiales y Métodoos}

\section{Lugar de Estudio y Animales}

El lugar de estudio se llevó a cabo en la provincia de Huaytará (distritos de Pilpichaca, San Antonio de Cusicancha, Tambo y Huayacundo Arma) del departamento de Huancavelica, Perú, zona que se encuentra entre 2726 a $4787 \mathrm{msnm}$ y posee una temperatura media anual de $10^{\circ} \mathrm{C}$ (INEI, 2012). Las muestras fueron procesadas en el Laboratorio de Parasitología de la Facultad de Veterinaria y Zootecnia de la Universidad Peruana Cayetano Heredia, en Lima. El trabajo de investigación fue aprobado por el Comité Institucional de Ética para Uso de Animales (CIEA) de la Universidad Peruana Cayetano Heredia, con código de inscripción N. ${ }^{\circ} 100514$.

El tamaño de muestra se determinó usando la fórmula de comprobación de una proporción en proporciones finitas, obteniéndose un tamaño mínimo muestral de 194 alpacas. Se consideró un tamaño de la población de 71386 , nivel de confianza al $95 \%$, una proporción anterior (conocida) de 14.8\% (Chávez-Velásquez et al., 2014) y una precisión de 0.05 . Se llegó a muestrear 288 alacas hembras de los cuatro distritos por conveniencia, los cuales presentan características geográficas similares. Las alpacas pertenecían a pequeños ganaderos y el número de animales muestreados por hato alpaquero fue entre 10 y 25 animales.

\section{Muestras}

Se tomaron muestras de sangre $(5-7 \mathrm{ml})$ por punción directa de la vena yugular, utilizando agujas hipodérmicas de $21 \mathrm{~g}$ y tubos estériles sin aditivos. Las muestras de sangre colectadas fueron enviadas en refrigeración al laboratorio y dentro de las 24 horas de su colección fueron centrifugadas a $1200 \mathrm{~g}$ por $5 \mathrm{~min}$. Los sueros resultantes fueron conservados en viales en congelación. Paralela- mente se levantó información situacional y epidemiológica de los rebaños muestreados (nombre y tipo de explotación, procedencia, edad, presencia de perros, número de pariciones, manejo de residuos orgánicos, presencia de otros animales).

Los sueros fueron procesados mediante la técnica de IFI. Se consideró animales positivos aquellos con un título de anticuerpos anti Neospora igual o mayor a 1:100 (ChávezVelásquez et al., 2004). En la prueba se utilizó suero de alpacas positivo y negativo a anticuerpos frente a Neospora control positivo, confirmado por Western Botting, como controles positivos y negativos, respectivamente.

Los sueros positivos fueron titulados, para lo cual se usaron láminas con el antígeno, realizando diluciones de 1/100, 1 / $200,1 / 400,1 / 800,1 / 1600$ y $1 / 3200$, siguiendo el procedimiento descrito para la técnica de IFI. Se utilizaron sueros positivos y negativos a sueros de alpacas de Huaytará, positivos y negativos, respectivamente, a anticuerpos frente a Neospora, confirmado por Western Blotting. Se consideró como suero positivo aquellos con fluorescencia completa del taquizoito y como sueros negativos aquellos con fluorescencia parcial o nula del taquizoíto.

\section{Análisis Estadístico}

Los resultados fueron expresados en porcentaje y con los intervalos de confianzas de $95 \%$. Se evaluó la asociación entre las variables edad, lugar de procedencia y número de partos con la presencia de anticuerpos específicos frente a $N$. caninum utilizando la prueba de Chi cuadrado.

\section{Resultados}

Todos los hatos muestreados pre-sentaron una crianza de tipo extensiva, contaban con una media de tres perros por hato (ran- 
Cuadro 1. Seroprevalencia de Neospora caninum en alpacas de la provincia de Huaytará, de Huancavelica, mediante la técnica de Inmunofluorescencia Indirecta (IFI), según el distrito de procedencia (2016-2017)

\begin{tabular}{lcc}
\hline Distrito & $\begin{array}{c}\text { Animales } \\
(\mathrm{n})\end{array}$ & $\begin{array}{c}\text { Positivo } \\
\mathrm{s}(\%)\end{array}$ \\
\hline $\begin{array}{l}\text { Pilpichaca } \\
\text { San Antonio } \\
\text { de Cusicancha }\end{array}$ & 114 & 20.2 \\
$\begin{array}{l}\text { Tambo } \\
\text { Huayacundo }\end{array}$ & 97 & 18.2 \\
Arma & 22 & 11.3 \\
Total & 288 & $\begin{array}{c}16.3 \pm \\
4.3\end{array}$ \\
\hline
\end{tabular}

go: 2-5), tenían un mal manejo de residuos orgánicos (se alimentaba a los canes con vísceras crudas) y había presencia de animales silvestres como zorros, roedores y aves.

La seroprevalencia de anticuerpos frente a $N$. caninum fue de $16.3 \pm 4.3 \%$ (47/ 288). La seroprevalencia por distrito se muestra en el Cuadro 1, por grupo etario en el Cuadro 2 y por número de partos en el Cuadro 3, no encontrándose diferencias significativas entre distritos, grupos etarios ni por número de parto.

De las 47 muestras positivas a $N$. caninum, el $61.7 \%$ (29) presentaron títulos de $1: 100$, el $29.8 \%$ (14) con 1:200, el 6.4\% (3) con $1: 400$ y el $2.1 \%$ (1) con $1: 800$, no encontrando seropositividad en diluciones igual o superiores a 1/1600 (Cuadro 4).

\section{Discusión}

El $16.3 \pm 4.3 \%$ de seroprevalencia de anticuerpos contra $N$. caninum en alpacas fue bastante más alto que el 3.1\% (10/319) reportado por Wolf et al. (2005) a través de
Cuadro 2. Seroprevalencia de N. caninum en alpacas de la provincia de Huaytará, de Huancavelica, mediante la técnica de Inmunofluorescencia Indirecta (IFI), según el grupo etario (2016-2017)

\begin{tabular}{lcc}
\hline $\begin{array}{l}\text { Grupo etario } \\
\text { (años) }\end{array}$ & $\begin{array}{c}\text { Animales } \\
(\mathrm{n})\end{array}$ & $\begin{array}{c}\text { Positivos } \\
(\%)\end{array}$ \\
\hline $1-2$ & 51 & 9.8 \\
$>2-3$ & 45 & 15.6 \\
$>3-4$ & 68 & 13.2 \\
$>4$ & 124 & 20.9 \\
\hline Total & 288 & $16.3 \pm 4.3$ \\
\hline
\end{tabular}

Cuadro 3. Seroprevalencia de N. caninum en alpacas de la provincia de Huaytará, de Huancavelica, mediante la técnica de Inmunofluorescencia Indirecta (IFI), según número de partos (2016-2017)

\begin{tabular}{lcc}
\hline $\begin{array}{l}\text { Número de } \\
\text { partos }\end{array}$ & $\begin{array}{c}\text { Animales } \\
(\mathrm{n})\end{array}$ & $\begin{array}{c}\text { Positivos } \\
(\%)\end{array}$ \\
\hline Nulípara & 51 & 7.8 \\
Primípara & 52 & 13.5 \\
Multípara & 185 & 19.5 \\
\hline Total & 288 & $16.3 \pm 4.3$ \\
\hline
\end{tabular}

ELISA e IFI con un punto de corte de 1/50 en alpacas de Quimsachata, Puno, aunque menor al 42.4\% (39/92) encontrado por Chávez et al. (2002) usando IFI con un punto de corte de 1/50 en alpacas de centros comuneros del centro del país. En estudios más actuales, Chávez-Velásquez (2014) reportan una prevalencia de $14.8 \%$ (425/2874) mediante IFI. Por otra parte, Moya et al. (2003) indicaron una seroprevalencia de $16.7 \%$ (46/275) en llamas de Melgar, Puno. Las diferencias entre estudios podrían deberse a factores como zonas o regiones de muestreo, tipo de explotación, punto de corte, presencia de hospederos intermediarios y definitivos, cercanía a la ciudad, clima y altitud (Dubey, 2010). 
Cuadro 4. Títulos de anticuerpos frente a Neospora caninum en alpacas de la provincia de Huaytará, Huancavelica, mediante la técnica de Inmunofluorescencia Indirecta (2016-2017)

\begin{tabular}{ccccccc}
\hline Alpacas & Positivos & $1 / 100$ & $1 / 200$ & $1 / 400$ & $1 / 800$ & $1 / 1600$ \\
\hline $\mathrm{n}$ & 47 & 29 & 14 & 3 & 1 & 0 \\
$\%$ & 100 & 61.7 & 29.8 & 6.4 & 2.1 & 0 \\
\hline
\end{tabular}

El tipo de explotación extensiva, donde los animales recorren grandes extensiones de pastoreo y se relacionan con otras especies como ovinos, llamas, caballos y perros favorece el desarrollo de la parasitosis. Se pudo observar que todas las comunidades y hatos alpaqueros tenían entre 2 a 5 canes. Así mismo, se encontró la presencia de roedores, aves y caninos silvestres como el zorro andino (Pseudalopes culpaeus), el cual no se ha demostrado que pueda actuar como hospedero definitivo de N. caninum (Cañón et al., 2004).

Si bien no se encontró diferencia significativa a la infección por $N$. caninum, debido al grupo etario, se vio una tendencia de incrementarse a medida que avanza la edad, ya que animales de mayor edad presentan más tiempo de exposición a la infección (Barberan y Marco, 1997). En forma similar, se observó una tendencia a incrementarse la frecuencia de infección con el número de partos, considerando que a mayor número de gestaciones se tiene más edad, aunado al estrés de pre- y posparto (Quevedo et al., 2003).

Las pequeñas diferencias entre distritos podrían deberse a la cercanía de los hatos a la ciudad. Casas et al. (2006) observaron que la prevalencia a la parasitosis aumentaba cuando los animales eras trasladados a zonas bajas, cercanas a los poblados, para realizar faenas de campo. Esto implicaría una mayor concentración de alpacas en áreas pequeñas y un mayor contacto con hospederos definitivos.

\section{Conclusiones}

- La seroprevalencia de $16.3 \%$ de Neospora caninum en alpacas de la provincia de Huaytará, Huancavelica, es considerada moderada.

- Las variables edad, procedencia y número de partos no estuvieron asociadas a la presencia de infecciones por $N$. caninum.

- Los títulos de anticuerpos contra $N$. caninum fueron bajos.

\section{Agradecimientos}

Los autores agradecen a Cienciactiva del CONCYTEC por el apoyo financiero brindado al proyecto «Obtención y caracterización del primer aislado de Neospora caninum causante de abortos en camélidos sudamericanos del Perú, con fines inmunodiagnóstico y vacunal» (Convenio de Gestión N. ${ }^{\circ} 220-$ 2015 FONDECYT-De), que permitió los análisis y la capacitación técnica de los investigadores para la ejecución del estudio. 


\section{Literatura Citada}

1. Aguilar M, Torres D, Murillo R, Zeballos J. 2014. Buenas prácticas de manejo en la producción de alpacas. Arequipa: DESCO. $122 \mathrm{p}$.

2. Atkinson RA, Cook RW, Reddacliff LA, Rothwell J, Broady KW, Harper P, Ellis JT. 2000. Seroprevalence of Neospora caninum infection following an abortion outbreak in dairy cattle herd. Aust Vet J 78: 262-266. doi: 10.1111/ j.1751-0813.2000.tb11752.x

3. Barberan M, Marco JC. 1997. Patogenia, cuadro clínico y lesional en toxoplasmosis-neosporosis. Rev Aula Vet OVIS 52: 35-48.

4. Baszler TV, Knowles DP, Dubey JP, Gay JM, Mathison BA, McElwain TF. 1996. Serological diagnosis of bovine neosporosis by Neospora caninum monoclonal antibody-based competitive inhibition enzyme-linked immunosorbent assay. J Clin Microbiol 34: 1423-1428.

5. Björkman C, Uggla A. 1999. Serological diagnosis of Neospora caninum infection. Int J Parasitol 29: 1497-1507. doi: 10.1016/S0020-7519(99)00115-0

6. Cañón-Franco WA, Yai LE, Souza SL, Santos LC, Farias NA, Ruas J, Rossi $F W$, et al. 2004. Detection of antibodies to Neospora caninum in two species of wild canids, Lycalopex gymnocercus and Cerdocyon thous from Brazil. Vet Parasitol 123: 275-277. doi: 10.1016/ j.vetpar.2004.06.004

7. Casas G, Chávez A, Casas E, Leyva V, Alvarado A, Serrano E, Ticona D, et al. 2006. Presencia de Neospora caninum en llamas de una empresa ganadera de la sierra central. Rev Inv Vet Perú 17: 8-13. doi: 10.15381/ rivep.v17i1.1450

8. Chávez A, Serrano E, Casas E, Ortega LM. 2002. Neospora caninum en camélidos sudamamericanos peruanos. Rev Inv Vet Perú 13: 92-93. doi: 10.15381/rivep.v13i2.7338
9. Chávez A, Álvarez G, Collantes E, Casas E, Rosadio R, Serrano E, Ortega L. 2004. First report of Neospora caninum infection in adult alpacas (Vicugna pacos) and llamas (Lama glama). J Parasitol 90: 864-866. doi: 10.1645/GE-260R

10. Chávez-Velásquez A, AguadoMartínez A, Ortega-Mora L, CasasAstos E, Serrano-Martínez E, CasasVelásquez G et al. 2014. Toxoplasma gondii and Neospora caninum seroprevalences in domestic South American camelids of the Peruvian Andes. Trop Anim Health Pro 46: 11411148. doi: 10.1007/s11250-014-0618-1

11. Dubey J. 2003. Review of Neospora caninum and neosporosis in animals. Kor J Parasitol 41: 1-16. doi: 10.3347/ kjp.2003.41.1.1

12. Dubey J. 2010. Toxoplasmosis of animals and humans. $2^{\circ}$ ed. USA: CRC Press. 313 p.

13. Dubey JP, Schares G, Ortega-Mora LM. 2007. Epidemiology and control of neosporosis and Neospora caninum. Clin Microbiol Rev 20: 323-367. doi: 10.1128/CMR.00031-06

14. [FAO] Organización de las Naciones Unidas para la Agricultura y la Alimentación. 2005. Situación actual de los camélidos sudamericanos. Chile: FAO. 62 p. [Internet]. Disponible en: https://tarwi.lamolina.edu.pe/ emellisho/ zootecnia_archivos/situacion $\% 20$ alpcas $\% 20$ peru.pdf

15. Gallegos $R F$. 2013. Índices productivos de alpacas del centro de investigación producción «La Raya». Rev Invest Altoandina 15: 255-262

16. Gondim LF, McAllister MM, Pitt WC, Zemlicka DE. 2004. Coyotes (Canis latrans) are definitive hosts of Neospora caninum. Int J Parasitol 34: 159-161. doi: 10.1016/j.ijpara.2004.01.001

17. [INEI] Instituto Nacional de Estadística e Informática. 2012. [Internet]. Disponible en: https://www.inei.gob.pe/ estadisticas/censos/ 
18. Llanos R, Morales M. 2012. Sanidad y salud animal en camélidos. Preparación y reducción de riesgos en respuesta a los eventos climáticos extremos y los problemas de disponibilidad de agua en comunidades vulnerables del altiplano de Bolivia y Perú. FAO. [Internet]. Disponible en: http://www.fao.org/3/aas961s.pdf

19. McAllister M, Dubey J, Lindsay D, Jolley WR, Wills R, McGuire A. 1998. Dogs are definitive hosts of Neospora caninum. Int J Parasitol 28: 1473-1478. doi: 10.1016/S0020-7519(98)00138-6

20. Moya R, Chávez, A, Casas E, Serrano E, Falcón N, Pezo D. 2003. Seroprevalencia de Neospora caninum en llamas de la provincia de Melgar, Puno. Rev Inv Vet Perú 14: 155-160. doi: 10.15381/rivep.v14i2.1621

21. Quevedo J, Chávez A, Rivera H, Casas E, Serrano E. 2003. Neosporosis en bovinos lecheros en dos distritos de la provincia de Chachapoyas. Rev Inv Vet Perú 14: 33-37. doi: 10.15381/ rivep.v14i1.1594
22. Sager H, Fischer I, Furrer K, Strasser M, Waldvogel A, Boerlin P, Audigé L, et al. 2001. A Swiss case-control study to assess Neospora caninum-associated bovine abortions by PCR, histopathology and serology. Vet Parasitol 200: 1-15. doi: 10.1016/S0304-4017(01)00524-6

23. Serrano-Martínez E, CollantesFernández E, Chávez-Velásquez A, Rodríguez-Bertos A, Casas-Astos E, Risco-Castillo V, et al. 2007. Evaluation of Neospora caninum and Toxoplasma gondii infections in alpaca (Vicugna pacos) and llama (Lama glama) aborted foetuses from Peru. Vet Parasitol 150: 39-45. doi: 10.1016/j.vetpar.2007.08.048

24. Wolf D, Schares G, Cárdenas O, Huanca W, Cordero A, Barwald A, Conraths F, et al. 2005. Detection of specific antibodies to Neospora caninum and Toxoplasma gondii in naturally infected alpacas (Lama pacos), llamas (Lama glama) and vicuñas (Lama vicugna) from Peru and Germany. Vet Parasitol 130: 81-87. doi: 10.1016/ j.vetpar.2005.03.024 